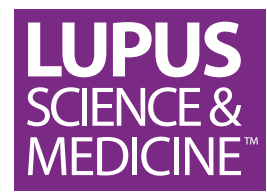

\title{
Assessment of SLE activity for acute clinical decision-making: use of a colour-coded threat-level approach for the non-rheumatologist
}

\author{
Cindy Flower
}

To cite: Flower C. Assessment of SLE activity for acute clinical decision-making: use of a colour-coded threat-level approach for the non-rheumatologist. Lupus Science \& Medicine 2021;0:e00484. doi:10.1136/ lupus-2021-000484

Received 21 January 2021 Accepted 27 January 2021
Check for updates

(c) Author(s) (or their employer(s)) 2021. Re-use permitted under CC BY-NC. No commercial re-use. See rights and permissions. Published by BMJ.

Faculty of Medicine, University of the West Indies, Cave Hill Campus, Barbados

Correspondence to Dr Cindy Flower; cflower@ caribsurf.com

\section{ABSTRACT}

Systemic lupus erythematosus (SLE) activity indices are widely applied in academic centres and for research protocols but are often not part of usual care in busy under-resourced clinical settings especially where non-rheumatologists are involved in SLE management. We developed a simplified activity index based on the established knowledge and experience of SLE in our hospital and further applied a treatment guideline to assist in acute clinical decision-making. The index is colour-coded for easy reference and categorizes clinical complications in order of the severity of the threat they pose to the patient. An index such as this can be modified to have wider application and relevance in other countries with reduced access to specialist care.

SLE activity indices are useful in clinical monitoring of patients to identify those most at risk of adverse outcomes, to help guide management decisions, to determine the urgency of treatment and to evaluate response to such treatment. ${ }^{1}$ They can be used to assess the disease longitudinally, document patterns of disease and outcomes and record the attainment of low lupus disease activity state, which is emerging as a reasonable therapeutic target. ${ }^{2}$

SLE activity indices are typically applied in clinical trials and in specialist centres. ${ }^{3}$ They are often not used as part of usual care in busy clinical practices or by nonspecialist medical practitioners. In small island developing states such as the islands of the Caribbean, there is a dearth of rheumatologists in spite of the high prevalence of SLE, and there are resource limitations which challenge the use of the most commonly applied disease activity indices. The Systemic Lupus Erythematosus Disease Activity Index score may not accurately reflect disease severity, and some clinical manifestations of SLE are not represented. Additionally, some laboratory tests, for example, complements and anti-dsDNA titre, are not available in all clinical settings. The British Isles Lupus Assessment Group Index is complicated, requiring some training and experience. The Lupus Foundation of America Rapid Evaluation of Activity in Lupus clinicianreported outcome was developed to be an accurate and practical measure but has not yet been assessed when used by non-specialists. ${ }^{4}$

We embarked on the development of a locally relevant activity index based on established knowledge of the most common and severe clinical complications of SLE at our hospital. $^{5}$ The index covers various organ domains, is non-numerical and uses a simplified colour-coded threat-level approach inspired by the US Department of Homeland Security Advisory System for terrorist attacks, 2002-2011 ${ }^{6}$ (table 1).

It was styled to capture clinical data in suboptimal, resource-constrained settings and for use by non-specialists who are frequently at the forefront of SLE diagnosis and management. It was designed to help the non-specialist with therapeutic decision-making in the acute clinical encounter.

After initial clinical assessment of the patient, the doctor applies clinical reasoning and supportive investigations to determine whether the presenting features are due to one or more of the following: active SLE, secondary damage from SLE, a side effect of medication, an intercurrent illness and a concurrent disease. Once a clinical feature is attributed to active SLE, the index is applied. The index helps advise on how aggressively the patient's condition needs to be managed based on risk. If the clinical feature is not represented in the index, that feature is uncommon in our clinical setting and should prompt a rethink of 
Table 1 SLE colour-coded threat-level advisory system

\section{Severe}

Perilous organ complication

Major cause of death

Treatment as for high risk

Prioritised as a medical emergency

High

Major organ involvement

Risk of death

Treatment options

PulseMTP $500-750 \mathrm{mg} /$ day intravenous $\times 3$.

$>$ Prednisone $1 \mathrm{mg} / \mathrm{kg} / \mathrm{day}$.

CTX 0.5g-1.0 g, RTX 1g, MMF 2-3 g/day.

Background HCQ 5 mg/kg/day.

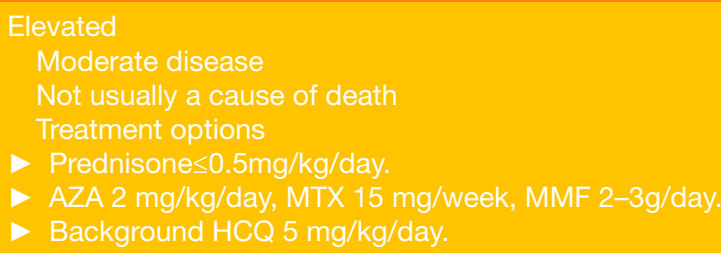

Guarded

Mild disease

Not a cause of death

Treatment options

- Topical steroids/NSAIDs.

- Prednisolone $<6 \mathrm{mg} /$ day.

- May require AZA, MTX.

- Background HCQ 5 mg/kg/day.

Low

Very low-risk complication

Not a cause of death

Treatment options

- Topical steroids/NSAIDs.

- Background HCQ 5 mg/kg/day.

Organ domains Low Guarded High Severe

$\begin{array}{llll}\text { Mucocutaneous } & \text { Malar rash, } & \text { Extensive DLE, Vasculitic } & \text { Vasculitic ulcers } \\ \text { isolated DLE, } & \text { purpura/nodules, Scarring }\end{array}$

isolated DLE, purpura/nodules, Scarring

non-scarring alopecia

alopecia,

oral/nasal

ulceration

$\begin{array}{lll}\text { Musculoskeletal } & \text { Arthralgia } & \text { Polyarthritis } \\ \text { Cardiopulmonary } & \text { Mild pleuritis } & \text { Moderate/large pleural } \\ & \text { Mild pericarditis } & \text { effusion, shrinking } \\ & \text { lung syndrome or } \\ & \text { pneumonitis with } \\ & \text { exertional symptoms } \\ & \text { Moderate/large } \\ & \text { pericardial effusion }\end{array}$

\begin{tabular}{|c|c|c|c|c|c|}
\hline \multicolumn{4}{|l|}{ Renal } & $\begin{array}{l}\text { Proteinuria }>1 \mathrm{~g} \\
\text { Normal creatinine }\end{array}$ & $\begin{array}{l}\text { Proteinuria }>1 \mathrm{~g} \\
\text { elevated } \\
\text { creatinine }\end{array}$ \\
\hline \multicolumn{4}{|l|}{ Neuropsychiatric } & $\begin{array}{l}\text { Psychosis, seizures, } \\
\text { myelopathy, ACS }\end{array}$ & Stroke \\
\hline \multicolumn{4}{|l|}{ Ophthalmic } & retinal vasculitis & \\
\hline
\end{tabular}

ACS, acute confusional state; AlHA, autoimmune haemolytic anaemia; AZA, azathioprine; CTX, cyclophosphamide; DLE, discoid lupus erythematosus; MMF, mycophenolate mofetil; MTP, methylprednisolone; MTX, methotrexate; RTX, rituximab. 
attribution to SLE and additionally would indicate that expert opinion is needed. In our hospital, the most common disease-related causes of death in SLE are severe lupus nephritis and stroke. ${ }^{57}$ As a result, these complications are coded as 'severe', with this designation prioritising them for resources such as hospital or intensive care unit admission.

This system affords the opportunity for wider application through the modification of clinical domains based on knowledge and experience in the particular hospital or country in which it is to be used.

Contributors CF is the sole author and contributor to this work.

Funding The authors have not declared a specific grant for this research from any funding agency in the public, commercial or not-for-profit sectors.

Competing interests None declared.

Patient and public involvement Patients and/or the public were not involved in the design, conduct, reporting or dissemination plans of this research.

Patient consent for publication Not required.

Provenance and peer review Not commissioned; internally peer reviewed.

Open access This is an open access article distributed in accordance with the Creative Commons Attribution Non Commercial (CC BY-NC 4.0) license, which permits others to distribute, remix, adapt, build upon this work non-commercially, and license their derivative works on different terms, provided the original work is properly cited, appropriate credit is given, any changes made indicated, and the use is non-commercial. See: http://creativecommons.org/licenses/by-nc/4.0/.
ORCID iD

Cindy Flower http://orcid.org/0000-0003-4515-4444

\section{REFERENCES}

1 Castrejón I, Tani C, Jolly M. Indices to assess patients with systemic lupus erythematosus in clinical trials, long-term observational studies, and clinical care. Clin Exp Rheumatol 2014;32:S-85-95.

2 Tselios K, Gladman DD, Urowitz MB. How can we define low disease activity in systemic lupus erythematosus? Semin Arthritis Rheum 2019;48:1035-40.

3 Romero-Diaz J, Isenberg D, Ramsey-Goldman R. Measures of adult systemic lupus erythematosus: updated version of British Isles lupus assessment group (BILAG 2004), European consensus lupus activity measurements (ECLAM), systemic lupus activity measure, revised (SLAM-R), systemic lupus activity questionnaire for population studies (SLAQ), systemic lupus erythematosus disease activity index 2000 (SLEDAI-2K), and systemic lupus international collaborating Clinics/ American College of rheumatology damage index (SDI). Arthritis Care Res 2011;63 Suppl 11:S37-46.

4 Askanase AD, Nguyen SC, Costenbader K, et al. Comparison of the lupus Foundation of America-Rapid evaluation of activity in lupus to more complex disease activity instruments as evaluated by clinical Investigators or real-world clinicians. Arthritis Care Res 2018;70:1058-63.

5 Flower C, Hennis AJM, Hambleton IR, et al. Systemic lupus erythematosus in an African Caribbean population: incidence, clinical manifestations, and survival in the Barbados national lupus registry. Arthritis Care Res 2012;64:1151-8.

6 Department of Homeland Security. Available: www.dhs.gov/homelandsecurity-advisory-system

7 Flower C, Hambleton I, Corbin D, et al. The spectrum of neuropsychiatric lupus in a black Caribbean population: a report of the Barbados national lupus registry. Lupus 2017;26:1034-41. 